\title{
Efeito do metal de adição na resistência ao desgaste por deslizamento de um aço estrutural soldado por GMAW
}

\author{
Effect of filler material on sliding wear \\ resistance of a structural steel welded \\ by GMAW
}

\author{
Daniela Fátima Giarollo ${ }^{1}$, Cíntia Cristiane Petry Mazzaferro ${ }^{1}$, \\ José Antônio Esmerio Mazzaferro
}

\footnotetext{
${ }^{1}$ Laboratório de Soldagem \& Técnicas Conexas (LS\&TC), Universidade Federal do Rio Grande do Sul, Porto Alegre, Rio Grande do Sul, Brasil.

e-mail: danielagiarollo@hotmail.com, cintia.mazzaferro@ufrgs.br, mazza@ufrgs.br
}

\begin{abstract}
RESUMO
O objetivo do presente trabalho foi avaliar o efeito do metal de adição na soldagem, e das microestruturas resultantes, na resistência ao desgaste de juntas soldadas de um aço estrutural ASTM A242, que possui resistência à corrosão atmosférica e é utilizado na fabricação de vagões destinados ao transporte de minério. As amostras foram soldadas através do processo GMAW (Gas Metal Arc Welding), utilizando dois metais de adição que apresentam resistências mecânicas diferentes, AWS ER70S-6 e AWS ER80S-G. A resistência ao desgaste das amostras foi avaliada através de ensaios de microdesgaste por deslizamento linear recíproco, a seco e em uma solução contendo $0,05 \mathrm{M} \mathrm{NaCl}$, em três regiões da junta soldada: metal base (MB), metal de solda (MS) e zona afetada pelo calor de grãos grosseiros (ZAC-GG). Após a soldagem, foi observado um aumento nos valores médios de durezas do MS e da ZAC em relação à dureza inicial do metal base. Os resultados dos ensaios de microdesgaste mostraram que o MB apresentou a menor resistência ao desgaste, possivelmente devido à sua microestrutura, que facilitou o desgaste por deformação plástica. A ZAC-GG apresentou a maior resistência ao desgaste entre as três regiões analisadas. Comparando os ensaios realizados nas condições a seco e em solução foi observada uma redução nos valores de coeficiente de atrito quando adicionada uma solução ao sistema, e uma perda de volume das trilhas mais acentuada. Observou-se que a utilização do metal de adição de menor resistência mecânica produziu juntas soldadas com resistência ao desgaste comparável às juntas obtidas com o arame de maior resistência.
\end{abstract}

Palavras-chave: Soldagem GTAW, Microestruturas, Microdesgaste por Deslizamento, Aço Estrutural.

\begin{abstract}
The aim of the present work was to evaluate the effect of the filler material in the welding and its resulting microstructures on the wear resistance of welded joints of a structural weathering steel ASTM A242 used in wagons for mining. The samples were welded using the GMAW (Gas Metal Arc Welding) process using two filler materials which have different mechanical strength, AWS ER70S-6 and AWS ER80S-G. The wear resistance of the samples was evaluated using a linearly reciprocating sliding microwear test, dry and in a solution containing $0.05 \mathrm{M} \mathrm{NaCl}$, in three regions of the welded joint: base metal (BM), weld metal (WM) and coarse grained heat affected zone (CGHAZ).After welding, it was observed an increase in the mean hardness values of the MS and ZAC in comparison to the initial hardness of base metal with the use of both filler metals, and the hardness values in each of these regions were similar. The results of the microwear tests showed that BM presented the lowest wear resistance, possibly due to its microstructure, which facilitated wear by plastic deformation. The CGHAZ showed the highest wear resistance. Comparing the tests carried out under the dry and in solution conditions, a reduction in the coefficient of friction was observed when the solution was added to the system, and the volume loss of the tracks was more pronounced. It was observed that the use of the lower mechanical strength filler material produced welded joints with wear resistance comparable to the joints obtained with the higher strength filler material.
\end{abstract}

Keywords: Welding GMAW, Microstructures, Sliding Wear, Structural steel. 


\section{INTRODUÇÃO}

Um dos principais problemas a serem enfrentados nas indústrias de mineração é o desgaste sofrido pelas máquinas e equipamentos em geral. HOLMBERG et al. [1] apuraram que são gastos aproximadamente 210 bilhões de Euros ao ano em problemas causados pelas perdas por atrito e desgaste nas atividades de mineração no mundo todo. Deste total, $40 \%$ são gastos com perdas devido ao atrito, $27 \%$ são destinados à reposição de peças e equipamentos desgastados, $26 \%$ são empregados em manutenção e $7 \%$ são perdas de produção. Além disso, atrito e desgaste na mineração são responsáveis por aproximadamente $3,4 \%$ da energia total consumida no mundo, sendo também responsáveis por 970 milhões de toneladas de $\mathrm{CO}_{2}$ emitidas anualmente para a atmosfera (2,7\% das emissões de $\mathrm{CO}_{2}$ no mundo).

Muitos dos componentes e estruturas são submetidos a processos de soldagem e as regiões das uniões também são expostas ao desgaste. Todavia, sabe-se que o desgaste apresentado por estas diverge do observado no restante das estruturas (metal base) devido a variações das microestruturas e propriedades mecânicas das juntas que são inerentes dos processos de soldagem. Atualmente, a maior parte dos estudos que envolvem desgaste em aplicações soldadas trata da aplicação de revestimentos duros em superfícies susceptíveis ao desgaste $[2,3,4,5,6]$, utilizando ligas complexas como metais de adição para a obtenção de depósitos com elevada quantidade de carbonetos. A resistência ao desgaste dos revestimentos é normalmente avaliada através de ensaios de desgaste abrasivos ou por deslizamento, mas independentemente do tipo de ensaio, a literatura indica que os mecanismos dominantes envolvem corte, deformação plástica, adesão e arrancamento de material, e que a atuação e/ou predominância de um ou outro mecanismo depende da dureza e da microestrutura do depósito.

No entanto, é indispensável dedicar maior atenção às juntas soldadas que utilizam aço carbono de baixa liga como metal de adição. Nestes casos é necessário que o metal de adição seja escolhido e utilizado adequadamente, assim como os parâmetros de soldagem, a fim de promover uma solda livre de defeitos, possuindo características como resistência ao desgaste, resistência mecânica e durezas semelhantes ou mesmo superiores às do metal base [7]. GARCÍA et al [8] estudaram o comportamento em desgaste abrasivo utilizando o equipamento do tipo pino-sobre-disco, em uma junta soldada pelo processo GTAW (Gas Tungsten Arc Welding) utilizando diferentes tratamento térmicos pré- e pós-soldagem, em um aço A355. Foram avaliadas as resistências ao desgaste do metal base, metal de solda e zona afetada pelo calor. Os resultados mostraram que as microestruturas nas diferentes regiões da junta soldada exerceram uma influência significativa sobre a resistência ao desgaste, sendo que em todos os casos analisados (sem tratamento e utilizando tratamento pré e pós-soldagem) a região que apresentou a maior resistência ao desgaste foi a zona afetada pelo calor (ZAC).

ROJACZ et al [9] analisaram o efeito da microestrutura obtidas pelo processo de soldagem GMAW em diferentes aços estruturais quanto às suas resistências à abrasão em altas temperaturas. Os resultados indicaram uma forte dependência da dureza e da microestrutura, originadas de diferentes parâmetros de soldagem, na resistência ao desgaste. Neste estudo, menores resistências ao desgaste foram observadas em microestruturas contendo ripas de martensita mais grosseiras, ou microestruturas que continham maior quantidade de ferrita.

Com o objetivo de verificar o comportamento em desgaste de juntas soldadas, no presente trabalho chapas de um aço estrutural ASTM A242 foram soldadas através do processo GMAW (Gas Metal Arc Welding) empregando os metais de adição AWS ER70S-6 e AWS ER80S-G. No Brasil este aço vem sendo utilizado, entre outros, na fabricação de vagões destinados ao transporte de minério. Nesta aplicação, corrosão e desgaste podem ocorrer simultaneamente, uma vez que durante a utilização os vagões recebem grande quantidade de minério (abrasivo) apresentando umidade e permanecem em vagões abertos durante a viagem, podendo receber mais umidade proveniente de chuvas. Para isso, foi avaliada a influência da microestrutura e da dureza de diferentes regiões das juntas soldadas nos ensaios de microdesgaste por deslizamento linear recíproco efetuados a seco e em uma solução contendo $0,05 \mathrm{M} \mathrm{NaCl}$.

\section{MATERIAIS E MÉTODOS}

O metal base utilizado neste estudo foi o aço estrutural de alta resistência e baixa liga (ASTM A242). Sua composição química e microestrutura são apresentadas na Tabela 1 e Figura 1, respectivamente. Observa-se em sua composição um baixo teor de carbono $(<0,1 \%)$ e a adição de outros elementos de liga, como $\mathrm{Cu}, \mathrm{Cr}$, $\mathrm{Ni}, \mathrm{Si}$ e Mn. A adição de Cu neste material proporciona uma maior resistência à corrosão atmosférica, pois durante a exposição ao ambiente, uma camada adesiva, compacta e protetora de produtos de corrosão, conhecida como pátina, cresce sob a superfície, retardando a corrosão adicional [10]. A microestrutura do aço é composta por ferrita e perlita e ele apresentava dureza de 190,1 $\pm 3,8 \mathrm{HV}$, obtida na direção normal à de laminação, que é aquela onde os ensaios de desgaste serão efetuados, como será descrito posteriormente. 
Tabela 1: Composição química e propriedades mecânicas do metal base (ASTM A242) e dos metais de adição utilizados na soldagem.

\begin{tabular}{lccccccccccccc}
\hline & \multicolumn{1}{c}{ Composição Química (\% peso) } & \multicolumn{4}{c}{ Propriedades Mecânicas } \\
\hline Material & C & Mn & Si & Cu & Ni & Cr & Al & Nb & Fe $\begin{array}{c}\text { Resistência à } \\
\text { tração (MPa) }\end{array}$ & $\begin{array}{c}\text { Alongamento } \\
(\%)\end{array}$ \\
\hline ASTM A242 & 0,08 & 0,62 & 0,42 & 0,24 & 0,12 & 0,03 & 0,04 & 0,008 & Bal. & 465 & 33 \\
\hline AWS ER70S-6* & 0,08 & 1,50 & 0,90 & - & - & - & - & - & Bal. & 560 & 26 \\
\hline AWS ER80S-G* & 0,10 & 0,60 & 1,50 & 0,40 & - & - & - & - & Bal. & 625 & 26 \\
\hline
\end{tabular}

* Composição química e propriedades mecânicas conforme ESAB [11].

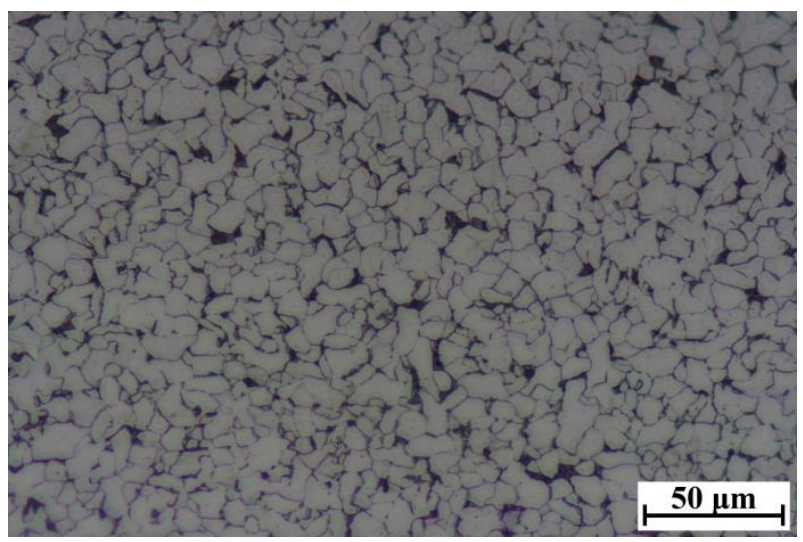

Figura 1: Microestrutura do material base: ferrita (fase clara) e perlita (fase escura). Ataque: Nital 10\%.

Para a soldagem dos corpos de prova, foi utilizado o processo de soldagem GMAW (Gas Metal Arc Welding) convencional com fonte ajustada para trabalhar no modo tensão constante e corrente contínua com eletrodo positivo $(\mathrm{CC}+)$. As soldas foram executadas por um sistema robotizado, composto por uma fonte Trans Plus Synergic 4000R da marca Fronius e pelo robô MA1400 da Yaskawa Motoman Robotics.

As dimensões iniciais das chapas do metal base eram $100 \times 200 \times 4,75 \mathrm{~mm}$. Uma vez que o foco deste trabalho é o estudo do desgaste em diferentes regiões de uma junta soldada obtida com o uso de um metal de adição de aço carbono baixa liga, que é o usualmente empregado na soldagem do aço ASTM A242, e objetivando a realização da soldagem em um único passe, foram utilizadas juntas de topo com chanfro em "V", com ângulo do chanfro $60^{\circ}$, abertura de raiz $1,2 \mathrm{~mm}$ e altura de raiz $2 \mathrm{~mm}$. Para a comparação do efeito do metal de adição, na soldagem foram utilizados dois tipos, o AWS ER70S-6 e o AWS ER80S-G, ambos com 1,2 mm de diâmetro. Na Tabela 1, estão apresentadas as suas composições químicas.

Observa-se que o metal de adição AWS ER80S-G, similarmente ao metal base, possui em sua composição química a adição de cobre, fator que o tornaria mais recomendado para a utilização neste aço, pois manteria o teor deste elemento no metal de solda comparável ao do metal base, conservando desta forma a sua resistência à corrosão atmosférica. Além disso, esses metais de adição também possuem resistências mecânicas distintas, como mostrado na Tabela 1, onde nota-se que a resistência do metal de adição AWS ER70S-6 é mais próxima à do aço em estudo, enquanto que a do metal de adição AWS ER80S-G é maior.

Os elementos de liga certamente influenciarão nas microestruturas (e durezas) formadas no metal de solda, que por sua vez afetarão a resistência ao desgaste, que é o foco da aplicação desse aço no presente estudo. No entanto, é importante salientar que os custos dos dois metais de adição são distintos, sendo mais elevado no caso do AWS ER80S-G. Os parâmetros de soldagem utilizados foram tensão de 22,6 V, velocidade de alimentação do arame de $5,2 \mathrm{~m} / \mathrm{min}$ e velocidade de soldagem de $4 \mathrm{~mm} / \mathrm{s}$. Houve uma pequena variação na corrente, resultando nos valores de 199,4 A e 224,0 A para os metais de adição AWS ER70S-6e AWS ER80S-G, respectivamente. Desta forma, as energias de soldagem foram $0,90 \mathrm{~kJ} / \mathrm{mm}$ para o metal de adição AWS ER 70S-6 e 1,02 kJ/mm para o AWS ER80S-G.

Neste processo foi utilizado o gás de proteção C25 (75\% de argônio e $25 \%$ de $\mathrm{CO}_{2}$ ), com vazão de 15 l/min, comumente empregado na soldagem de aços.

Após a soldagem, foram retirados corpos de prova das regiões centrais dos cordões para a realização dos ensaios de desgaste, visualização das microestruturas e análise de microdurezas, conforme esquema apresentado na Figura 2. As microestruturas foram observadas nas seções transversais ao cordão de solda, con- 
forme esquema da Figura 2 (III), para isso as amostras foram preparadas metalograficamente através de lixamento, utilizando lixas com granulometrias de até 1200 mesh, polimento com alumina e ataque utilizando Nital $10 \%$, as mesmas foram observadas em um microscópio ótico Zeiss Axio LabA.1. Para a determinação do percentual das fases presentes, foram obtidas dez imagens de cada região, após estas foram editadas utilizando o programa de edição de imagens ImageJ, a partir do qual foi possível estimar o percentual de cada fase.

Os perfis de microdureza foram obtidos por meio de leituras realizadas na face superior (seção normal) do cordão de solda, na mesma seção onde foram realizados os ensaios de desgaste, representada esquematicamente na Figura 2 (II). Para cada ponto representado foram realizadas 5 medições dentro de uma (sub) região de soldagem específica. Os valores de microdureza Vickers foram determinados utilizando-se um microdurômetro INSIZE, com carga de $300 \mathrm{~g}$ e tempo de indentação de $10 \mathrm{~s}$. Os ensaios de desgaste foram realizados na face superior do cordão de solda, paralelo à direção de soldagem. Para isso, amostras com dimensões aproximadas de $35 \mathrm{~mm}$ x $35 \mathrm{~mm}$ foram fresadas, retirando-se todo o reforço do cordão, após lixadas, polidas e atacadas, facilitando a visualização das diferentes regiões do cordão de solda e o posicionamento das amostras para a realização dos ensaios.

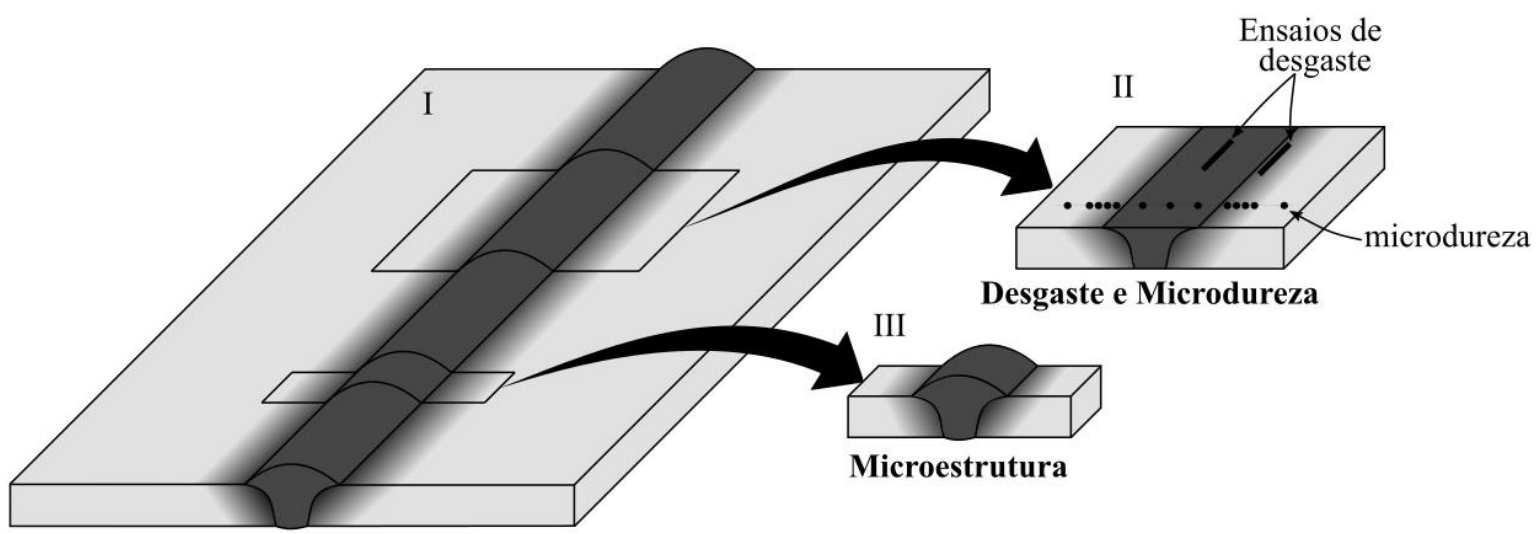

Figura 2: Esquema de uma junta soldada indicando os tipos de corpos de corpos de prova extraídos. I - amostra soldada; II - Corpos de prova para realização do ensaio de desgaste e microdureza e III - Corpos de prova para visualização de microestruturas.

Para a avaliação da resistência ao desgaste foi utilizado um equipamento de ensaios de microdesgaste por deslizamento linear recíproco com geometria de contato esfera-sobre-chapa, semelhante ao da norma ASTM G133 [12], porém utilizando parâmetros diferentes dos padronizados por ela, como descrito a seguir. Neste equipamento, o movimento linear é realizado pela amostra plana (material a ser analisado) e a carga é aplicada sobre a esfera, que permanece fixa. Estes ensaios foram realizados em duas condições: a seco e em uma solução contendo $0,05 \mathrm{M} \mathrm{NaCl}$. As amostras ensaiadas em solução eram imersas 15 minutos antes da inicialização do ensaio e permaneciam com solução durante todo o tempo de realização do mesmo. Optou-se por utilizar estes ensaios, devido à aplicação deste aço, onde tanto desgaste em condições a seco como o desgaste junto a um meio aquoso são passíveis de ocorrer.

Os ensaios foram realizados em três regiões distintas da junta soldada: metal base, metal de solda e zona afetada pelo calor de grãos grosseiros. Os ensaios na ZAC foram realizados na sub-região de grãos grosseiros, uma vez que ela usualmente é caracterizada por apresentar menores tenacidades e ser mais suscetível a fraturas, pois como está adjacente à linha de fusão, experimenta temperaturas de pico mais elevadas durante o ciclo térmico da soldagem, o que leva a um aumento no tamanho do grão austenítico e à formação de produtos de transformação mais duros $[13,14,15]$.

Uma esfera de alumina $\left(\mathrm{Al}_{2} \mathrm{O}_{3}\right)$ com 4,76 mm de diâmetro e dureza de aproximadamente $1500 \mathrm{HV}$ foi utilizada como contra-corpo. Definiu-se por utilizar a esfera cerâmica devido à sua alta dureza, resistência à oxidação e inércia química [16], minimizando a ocorrência de desgaste por adesão, e também a corrosão provocada pelos elementos utilizados no ensaio em solução. Os parâmetros utilizados nos ensaios foram: carga normal de $10 \mathrm{~N}$, amplitude da trilha de $2 \mathrm{~mm}$, velocidade de deslizamento $4 \mathrm{~mm} / \mathrm{s}$ e tempo de ensaio de 2 horas. Todos os ensaios foram realizados a temperatura ambiente. Para cada ensaio foram realizadas no mínimo três repetições.

Para a medição do coeficiente de atrito, o microtribômetro utiliza uma célula de carga, onde a partir da coleta de dados, um software de aquisição e controle faz a leitura e interpretação dos dados obtendo assim a 
força de atrito. Sendo assim, o coeficiente de atrito é obtido através da razão entre a força de atrito e a força normal aplicada. A média do coeficiente de atrito foi obtida após 15 minutos da inicialização do ensaio (após obter-se um regime permanente). O volume desgastado na esfera foi calculado de acordo com a norma ASTM G133 [12], para isso as marcas de desgaste foram medidas através de um microscópio ótico Zeiss Axio Lab A.1. Os volumes de desgaste nas trilhas (amostras planas) foram calculados a partir do produto de uma área média da seção transversal de desgaste (obtida com a utilização de um interferômetro a laser Bruker Contour-GT) e o comprimento da trilha. Os mecanismos de desgaste das trilhas foram observados através de um microscópio eletrônico de varredura (MEV) VEGA3 TESCAN.

\section{RESULTADOS E DISCUSSÃO}

Na Figura 3 são apresentas macrografias transversais ao cordão de solda e imagens da superfície e da raiz do cordão de solda. Observa-se com os parâmetros de soldagem empregados foi possível obter um cordão de solda com penetração completa e sem defeitos macroscópicos.

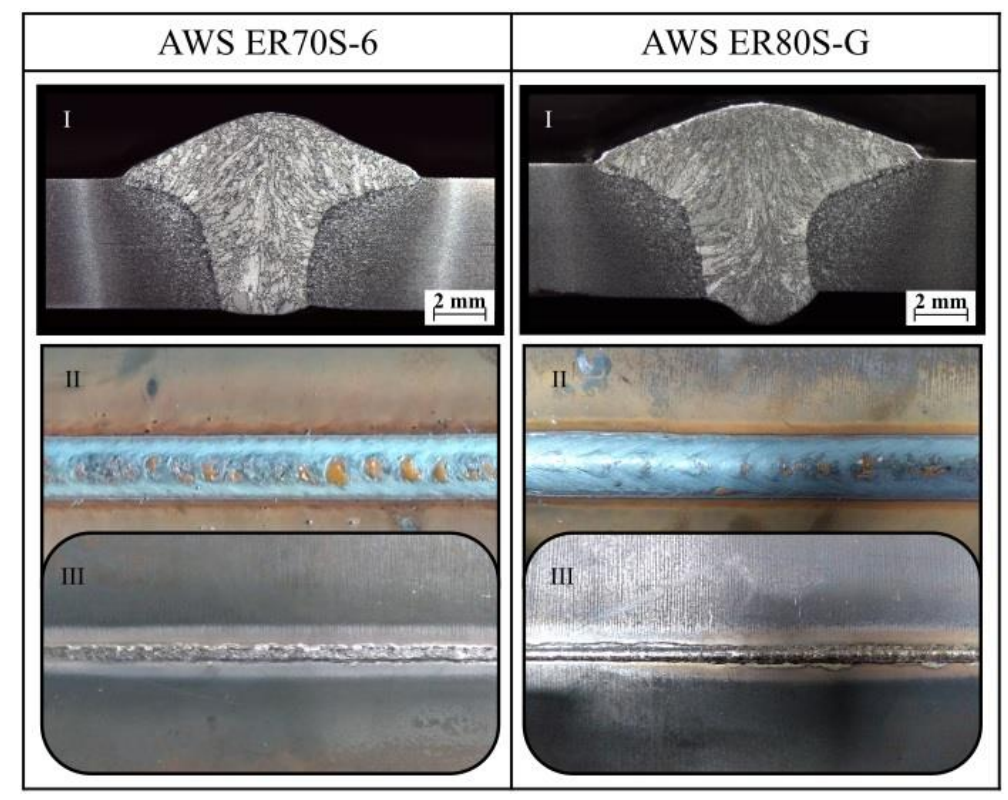

Figura 3: Aspectos dos cordões de solda: I - Macrografias transversais às direções de soldagem; II - Imagens da superfícies (faces) dos cordões e III - raiz dos cordões de solda.

\subsection{Análise microestrutural das juntas soldadas}

As microestruturas representativas dos metais de solda e das regiões de grãos grosseiros da ZAC (ZAC-GG) estão apresentadas nas Figuras 4 e 5, respectivamente. Na Figura 4 observam-se as microestruturas resultantes nos metais de solda, para os dois metais de adição utilizados. As microestruturas resultantes nestas regiões eram compostas predominantemente por ferrita de contorno de grão, ferrita poligonal intragranular, ferrita com segunda fase alinhada e ferrita acicular. Comparando as microestruturas obtidas para as duas condições, existe uma pequena variação na sua morfologia, onde se observa uma diminuição da ferrita de contorno de grão (foi observado aproximadamente $38 \%$ no MS-70 e $30 \%$ no MS-80) e aumento da ferrita acicular no metal de solda produzido com o metal de adição AWS ER80S-G (foi observado aproximadamente $60 \%$ no MS-70 e $68 \%$ no MS-80). Essas alterações se devem principalmente à composição química do metal de adição, porém também podem sofrer influência da diluição (AWS ER70S-6: 31,3 \% e AWS ER80S-G: 35,5 \%)e da variação de energia fornecida durante o processo de soldagem (AWS ER70S-6: 0,90 kJ/mm e AWS ER80S-G: 1,02 kJ/mm) [17].

Nas ZAC-GG, Figura 5, as microestruturas observadas foram ferrita de contorno de grão, ferrita de segunda fase alinhada e não alinhada, e agregados ferrita-carboneto. Neste caso, também foram observadas microestruturas muito semelhantes, sendo que a ZAC-GG-80, produzida na junta que utilizou o metal de adição AWS ER80S-G, apresentava regiões de ferrita de segunda fase alinhada e não alinhada maiores do que na ZAC-GG-70, que pertencia à junta obtida com o emprego do arame de adição AWS ER70S-6, foi observado aproximadamente $11,5 \%$ de ferrita de segunda fase alinhada e não alinhada na ZAC-GG -70 e aproximadamente $15 \%$ na ZAC-GG-80. 

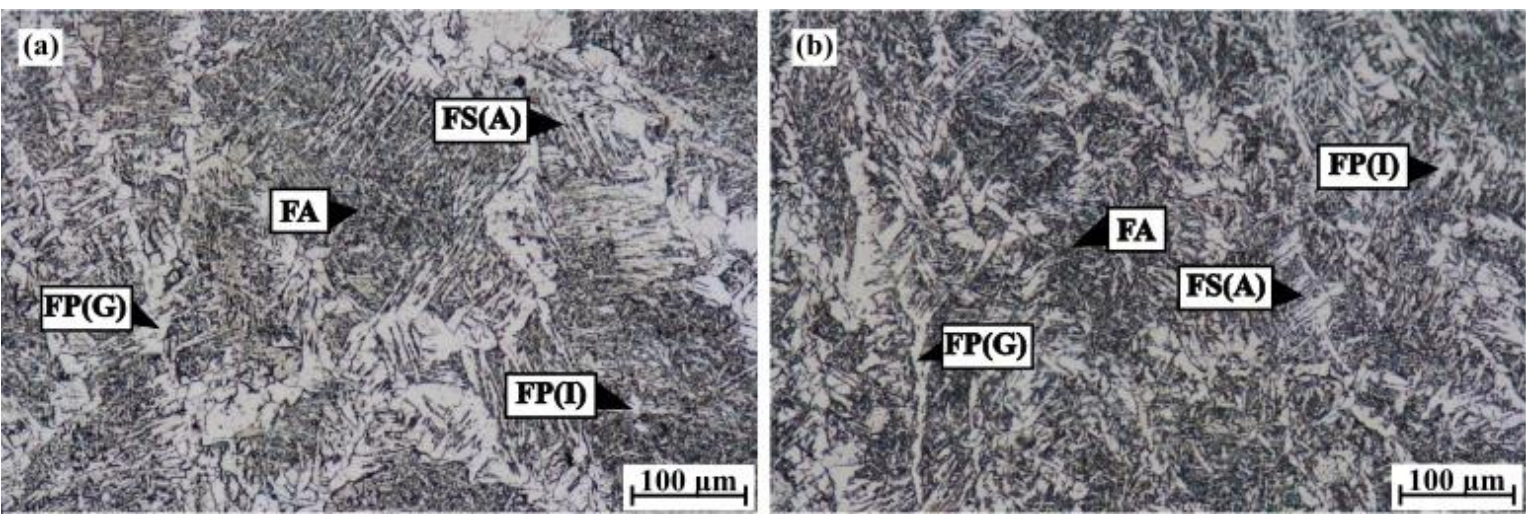

Figura 4: Microestrutura dos metais de solda, soldas realizadas com os metais de adição (a) AWS ER70S-6 (MS-70) e (b) AWS ER80S-G (MS-80). Microestruturas: FA - ferrita acicular, FP(G) - ferrita de contorno de grão, FP(I) - ferrita poligonal intragranular e FS(A) - ferrita de segunda fase alinhada.
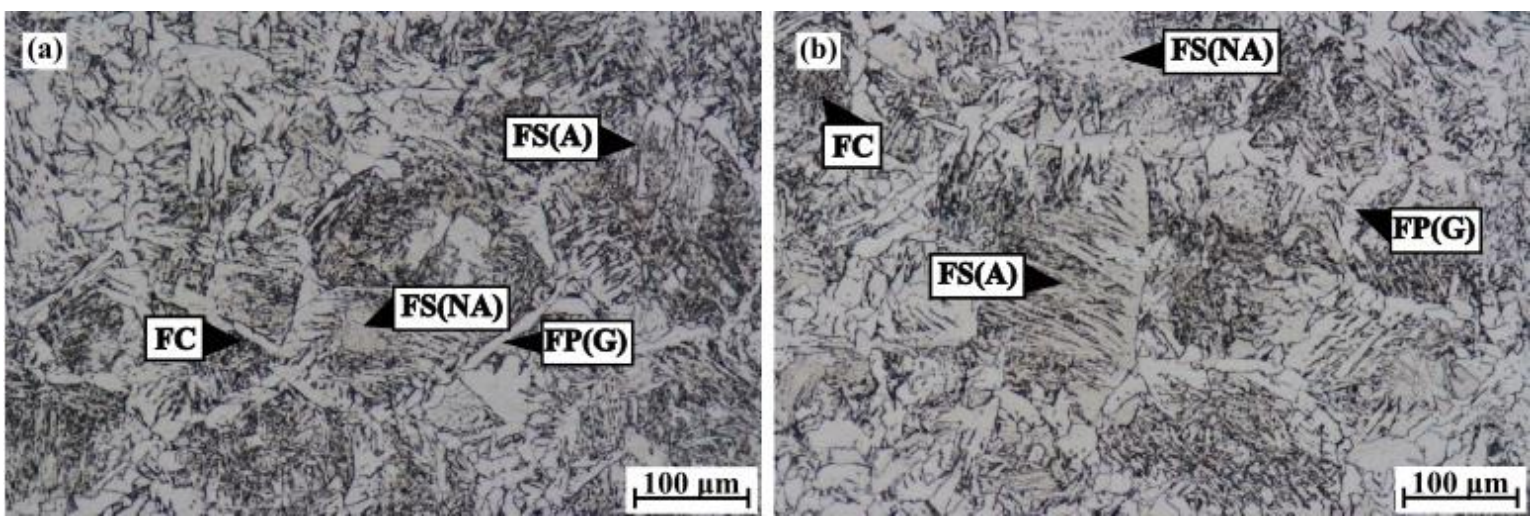

Figura 5: Microestruturas das ZAC-GG, soldas realizadas com os metais de adição (a) AWS ER70S-6 (ZAC-GG-70) e (b) AWS ER80S-G (ZAC-GG-80). Microestruturas: FP(G) - ferrita de contorno de grão, FS(A) e (NA) - ferrita de segunda fase alinhada e não alinhada, FC - agregado ferrita-carboneto.

\subsection{Variação da microdureza ao longo das juntas soldadas}

Na Figura 6 são apresentados os perfis de microdureza Vickers através das juntas soldadas, para cada metal de adição, na seção normal aos cordões de solda. Cada ponto representa uma média de cinco leituras de dureza dentro de sub-regiões específicas.
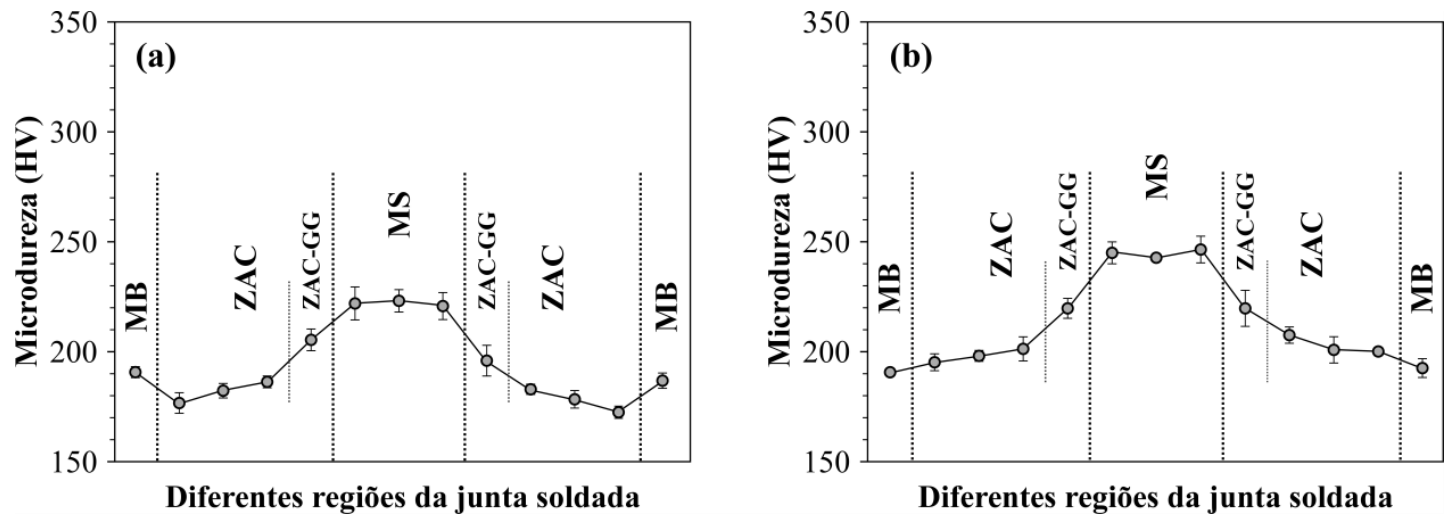

Figura 6: Variação da microdureza através das diferentes regiões das juntas soldadas obtidas com a utilização dos metais de adição: (a) AWS ER70S-6 e (b) AWS ER80S-G. 
Comparando-se os valores de durezas, com o uso de ambos os metais de adição observou-se um aumento nos valores médios de dureza dos MS e das ZAC em relação à dureza inicial do metal base, que era de $190,1 \pm 3,8 \mathrm{HV}$. Os valores de dureza foram maiores com o emprego do metal de adição AWS ER80S-G, e eram em média $20 \mathrm{HV}$ menores nas ZAC-GG do que nos MS, como mostrado na Tabela 2. Afastando-se da ZAC-GG em direção ao MB, houve uma diminuição nos valores de dureza nas demais sub-regiões da ZAC. A maior dureza observada da ZAC-GG em relação às demais sub-regiões decore da sua proximidade com a linha de fusão, o que faz com que esta região experimente temperaturas mais elevadas e taxas de resfriamento mais rápidas [18], levando à formação de microconstituintes mais duros.

Tabela 2: Valores médios de microdureza do MS e da ZAC-GG das juntas soldadas, para cada metal de adição utilizado.

\begin{tabular}{lll}
\multicolumn{2}{l}{ Microdureza } \\
\hline \multirow{2}{*}{ AWS ER70S-6 } & MS-70 & $221,9 \pm 6,2 \mathrm{HV}$ \\
\cline { 2 - 3 } & ZAC-GG-70 & $200,5 \pm 7,7 \mathrm{HV}$ \\
\hline AWS ER80S- & MS-80 & $244,8 \pm 4,7 \mathrm{HV}$ \\
\cline { 2 - 3 } G & ZAC-GG-80 & $219,8 \pm 6,5 \mathrm{HV}$ \\
\hline
\end{tabular}

\subsection{Ensaios de microdesgaste}

Como citado anteriormente, os ensaios de desgaste foram realizados no MB, e MS e ZAC-GG para as juntas produzidas com os dois metais de adição. Os dados em literatura referentes à resistência ao desgaste em juntas soldadas são escassos, então escolheu-se realizar os ensaios na região de grãos grosseiros da ZAC porque espera-se nela a formação de microestruturas com baixa tenacidade, o que poderia afetar negativamente a sua resistência ao desgaste. Os valores médios da perda de volume para cada condição e tipo de ensaio, a seco e em uma solução, estão apresentados na Figura 7.

Analisando os resultados dos ensaios de microdesgaste por deslizamento a seco, Figura 7(a), observou-se que o metal base sempre apresentou a maior perda de volume, seguido pelos metais de solda e então pelas ZAC-GG. Comparando as duas condições de soldagem nos desgastes a seco, o MS-70 apresentou uma perda de volume levemente superior ao MS-80, enquanto que nas ZAC-GG a perda de volume foi um pouco superior na ZAC-GG-80 em relação à ZAC-GG-70.
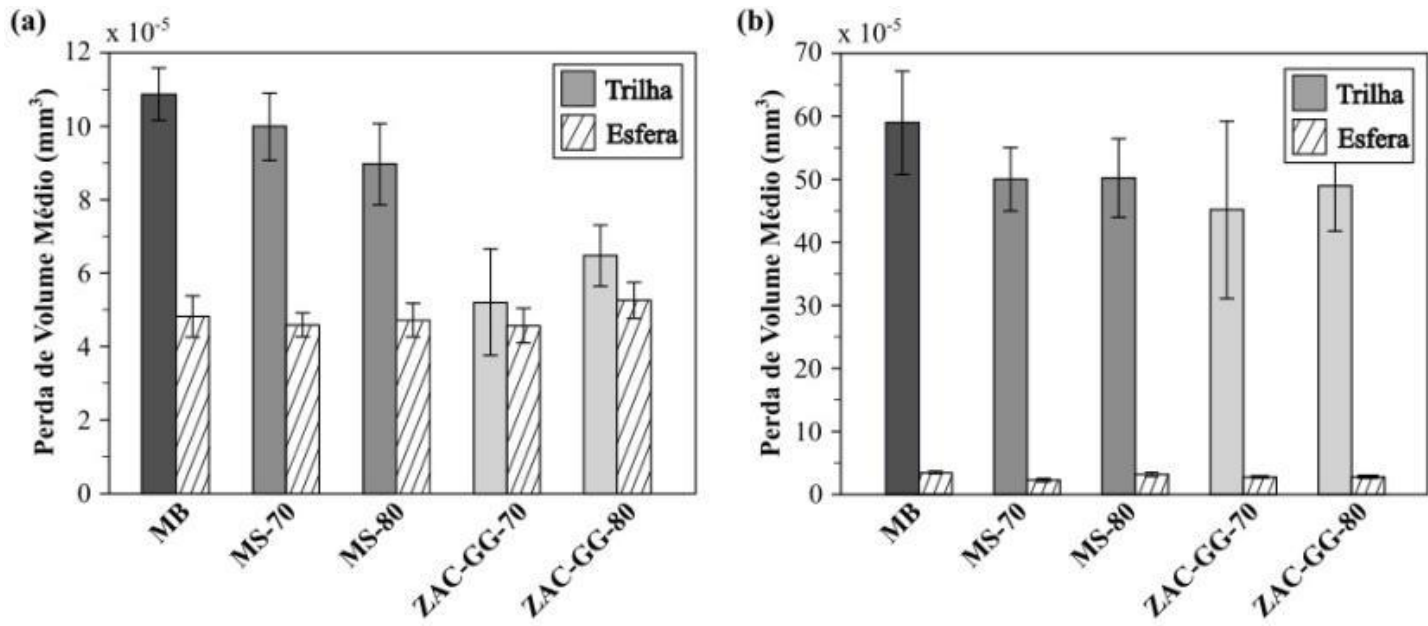

Figura 7: Perda de volume médio do metal base, metais de solda e zonas afetada pelo calor de grão grosseiro dos ensaios realizados nas condições (a) a seco e (b) imerso em solução.

Nos ensaios realizados em solução, Figura 7(b), o MB também apresentou a maior perda de volume, e não foi observada uma diferença significativa entre os volumes desgastados dos MS e das ZAC-GG. Comparando as duas condições ensaiadas, com e sem solução, observou-se que a perda de volume das trilhas quando em solução foi aproximadamente 6 vezes superior do que nos ensaios a seco.

Foi possível observar que o contra-corpo (esfera de alumina), apesar de apresentar dureza mais elevada do que os materiais das trilhas, também apresentou desgaste. Quando comparado ao volume desgastado das trilhas das ZAC-GG nas condições a seco, as perdas de volume das trilhas e das esferas foram próximas. Na Figura 8 são apresentadas imagens obtidas por microscopia ótica das superfícies de desgaste das esferas após 
os ensaios realizados no metal base, tanto nas condições a seco (Figura 8 (a)), quanto na condição em solução (Figura 8 (b)). Observa-se que as perdas de volume nas esferas tanto nas condições de ensaio a seco e em solução foram muito similares, mesmo as trilhas nos ensaios em solução apresentando maior perda de volume, o que indica que a presença da solução não alterou as propriedades/comportamento da esfera nesses ensaios de desgaste. Na Figura 8 também é possível observar o acúmulo de material removido das trilhas e provavelmente até mesmo da esfera, tanto nos ensaios a seco como nos ensaios em solução.
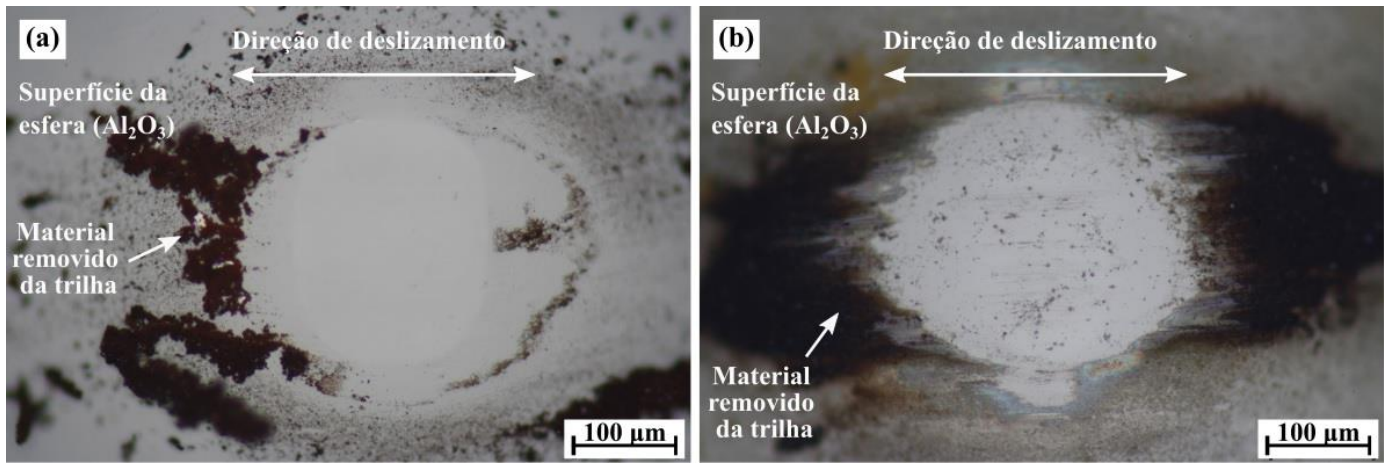

Figura 8: Aspectos das superfícies de desgaste (esfera de $\mathrm{Al}_{2} \mathrm{O}_{3}$ ) de ensaios realizados no $\mathrm{MB}$ nas condições (a) a seco e (b) em solução.

Micrografias das superfícies desgastadas obtidas através de MEV são apresentadas na Figura 9, apenas para MB e regiões da junta produzida com o AWS ER70S-6, uma vez que os resultados em todas as condições foram similares. As superfícies apresentavam deformação plástica, ranhuras (sulcos) e pequenas áreas onde houve a remoção de material, este último pode ter ocorrido através do mecanismo de desgaste por adesão, como observado por SINGLA [5] e CHO [19]. Em condições de deslizamento com solução, a deformação plástica foi menos intensa, o que pode ser comprovado observando-se os perfis transversais às trilhas de desgaste na Figura 10.

A maior deformação plástica do MB, como mostrado nas Figuras 10 (a) e (c), provavelmente decorre do fato de sua microestrutura possuir quantidade significativa de ferrita, fase dúctil e de baixa dureza. No entanto, alguns autores [20,21] citam que microestruturas compostas por colônias de perlita podem apresentar baixa resistência ao desgaste, uma vez que as partículas abrasivas ao deslizarem sobre o material são interrompidas por estas colônias, e provocam o seu arrancamento.

Apesar dos valores de dureza das ZAC-GG serem aproximadamente $10 \%$ menores do que os dos metais de solda, suas resistências ao desgaste foram superiores em aproximadamente $40 \%$. Esse comportamento possivelmente tenha decorrido de suas microestruturas, uma vez que o MS apresentava elevada quantidade de ferrita de contorno de grão e ferrita poligonal intragranular, fases que apresentam baixa dureza, o que provavelmente facilitou o desgaste através de deformação plástica. A ferrita acicular possui elevada tenacidade e resistência [22], o que pode ter contribuído para a resistência ao desgaste levemente superior do MS-80 em relação ao MS-70. As regiões com agregado ferrita-carboneto nas ZAC-GG podem ter restringido a remoção de material, uma vez que neste tipo de microestruturas existe a resistência à penetração de abrasivos, devido aos constituintes mais resistentes (carbonetos), e a resistência à iniciação e propagação de trincas, resultado das fases mais macias e dúcteis (ferrita) [23]. A não existência de uma relação direta entre dureza e resistência ao desgaste está de acordo com diversos autores [3, 5, 8, 21, 23, 24], que mostram que além da dureza, a microestrutura - fases presentes e suas morfologias - junto com a capacidade de deformação plástica são fatores determinantes na resistência ao desgaste dos materiais.

Comparando aos ensaios em condições a seco e em solução foi observado uma perda de volume na trilha muito mais acentuada, quando adicionada uma solução ao sistema. Nas Figuras 10 (b) e (d), observa-se que não houve uma deformação plástica significativa nas laterais das trilhas em nenhuma das regiões analisadas, para MB e ambos os metais de adição, o que indica que a presença da solução, que provoca a corrosão do material, foi determinante nos ensaios de resistência ao desgaste. Segundo FINDIK, [25] quando a corrosão e o desgaste ocorrem simultaneamente, os mecanismos atuam de forma sinérgica, e podem levar a uma degradação acelerada e significativa dos materiais em contato, uma vez que a reação química provocada pela solução em contato com a superfície do material pode promover a formação de uma camada de óxido com baixa durabilidade. Durante o desgaste essa camada permanece em constante formação e destruição, o que 
leva a uma acentuada perda de massa do material.

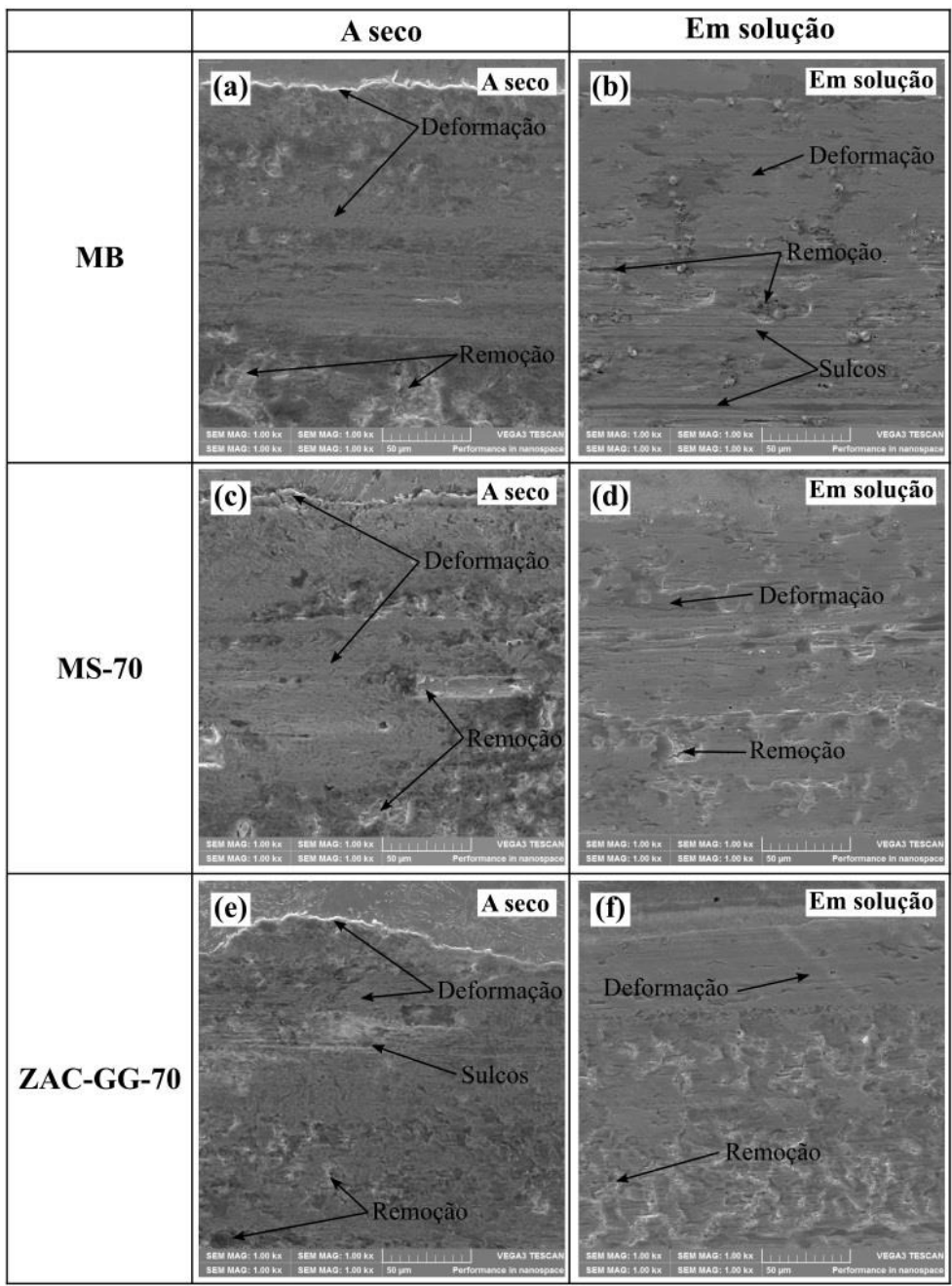

Figura 9: Aspecto das superfícies de desgaste (trilhas) de ensaios realizados nas condições a seco: (a) MB, (c) MS-70, (e) ZAC-GG-70; e em solução: (b) MB, (d) MS-70, (f) ZAC-GG-70.

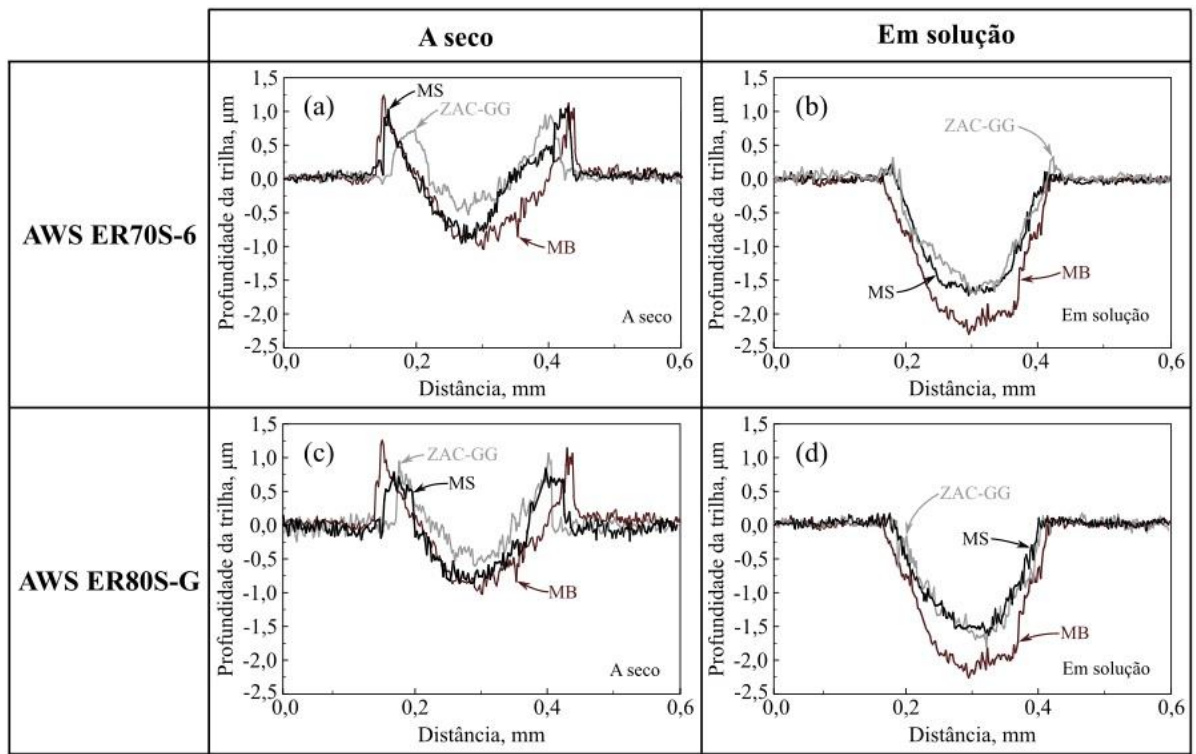

Figura 10: Perfil das seções transversais as trilhas de desgaste de ensaios realizados nas condições a seco: (a) AWS ER70S-6, e (c) AWS ER80S-G e em solução: (b) AWS ER70S-6 e (d) AWS ER80S-G. 
Os resultados de resistência ao desgaste, tanto a seco quanto em solução, mostraram que não houve diferenças significativas nos metais de solda ou nas zonas afetadas pelo calor com grãos grosseiros, obtidos com o emprego dos distintos metais de adição. Apesar dos maiores valores de dureza do MS e da ZAC-GG terem sido obtidos com a utilização do metal de adição AWS ER80S-G, as variações microestruturais em cada uma dessas zonas, quando comparadas ao metal de adição AWS ER70S-6, não influenciaram nas suas resistências ao desgaste. Como o metal de adição AWS ER80S-G possuía cobre, enquanto que o outro metal de adição não, esperava-se que o provável maior teor de cobre no MS-80 fosse mais efetivo na resistência ao desgaste em presença de solução do que o MS-70, mas esse fato não ocorreu, provavelmente devido à remoção contínua da camada de óxido formada, através do movimento da esfera. Sendo assim, os resultados do presente estudo mostraram que é mais vantajoso utilizar o metal de adição AWS ER70S-6, o qual possui menor custo comparado ao metal de adição AWS ER80S-G.

A Figura 11 representa o coeficiente de atrito $(\mathrm{CoF})$ em função do tempo de ensaios realizados no metal base em condições a seco e em solução. Segundo alguns autores [4, 26, 27], o CoF pode ser influenciado por muitos efeitos superficiais dos materiais, como rugosidade, dureza, condições de lubrificação e também interações químicas na interface entre o par tribológico. No presente trabalho, foi observada uma pequena variação no CoF entre os ensaios realizados nas diferentes regiões e utilizando os distintos metais de adição, como pode ser observado na Tabela 3, porém os valores foram fortemente influenciados quando a amostra foi imersa em uma solução. A lubrificação do par tribológico levou a uma redução no coeficiente de atrito de aproximadamente 0,1 , o que representa uma redução entre 15 e $30 \%$, valor esse que pode ser significativo em aplicações industriais.

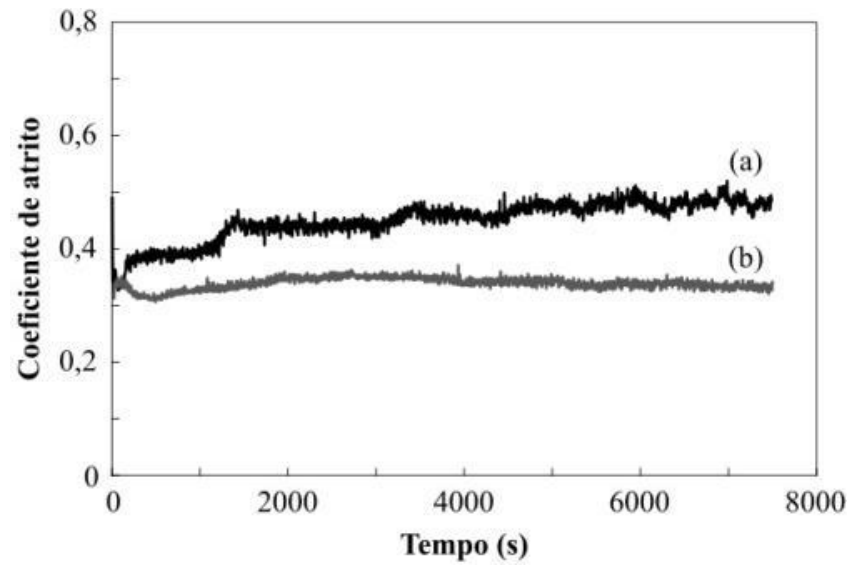

Figura 11: Curvas de coeficiente de atrito de ensaios realizados no MB nas condições (a) a seco e (b) em solução.

Tabela 3: Valores médios dos coeficientes de atrito dos ensaios realizados nas condições a seco e em solução para todas as regiões analisadas.

\begin{tabular}{lll}
\hline \multicolumn{2}{l}{ Coeficiente de Atrito* } \\
\hline & A seco & Em solução \\
\hline MB & $0,45 \pm 0,016$ & $0,32 \pm 0,007$ \\
\hline MS-70 & $0,43 \pm 0,023$ & $0,34 \pm 0,020$ \\
\hline MS-80 & $0,43 \pm 0,004$ & $0,35 \pm 0,015$ \\
\hline ZAC-GG-70 & $0,40 \pm 0,013$ & $0,34 \pm 0,015$ \\
\hline ZAC-GG-80 & $0,43 \pm 0,021$ & $0,36 \pm 0,007$ \\
\hline
\end{tabular}

*Valores médios obtidos após 15 minutos da inicialização do ensaio.

\section{CONCLUSÕES}

Neste trabalho, foi avaliado o efeito do processo de soldagem, metais de adição e microestruturas resultantes na resistência ao desgaste a seco e em uma solução de juntas soldadas de um aço estrutural ASTM A242 utilizado em vagões para o transporte de minérios. A partir dos resultados observados, as seguintes conclusões podem ser citadas:

As microestruturas resultantes nos metais de solda eram compostas predominantemente por ferrita de contorno de grão, ferrita poligonal intragranular, ferrita com segunda fase alinhada e ferrita acicular. Nas 
ZAC-GG, as microestruturas observadas foram ferrita de contorno de grão, ferrita de segunda fase alinhada e não alinhada, e agregados ferrita-carboneto;

Em termos de dureza, observou-se um aumento nos valores médios dos MS e das ZAC em relação à dureza inicial do metal base. Os valores de dureza na ZAC-GG, para as duas condições soldadas, foram aproximadamente $10 \%$ menores em relação aos dos metais de solda. Tanto na ZAC-GG quanto no metal de solda da condição soldada com o metal de adição AWS ER 80S-G, as durezas foram aproximadamente $10 \%$ superiores às do AWS ER70S-6.

Nos ensaios de microdesgaste por deslizamento a seco, as ZAC-GG foram as regiões que apresentaram as maiores resistências ao desgaste. No MB foi observada a maior perda de volume, aproximadamente $15 \%$ maior em relação aos metais de solda e $85 \%$ em relação à ZAC-GG. Entre as duas condições soldadas não foram observadas diferenças significativas em relação às suas resistências ao desgaste;

Nos ensaios realizados em solução, o MB também apresentou a menor resistência ao desgaste, aproximadamente $17 \%$ menor do que as demais regiões, MS e ZAC-GG. No entanto, não houve diferença significativa entre os resultados obtidos nessas regiões, e também não foram observadas diferenças em relação aos dois metais de adição utilizados;

Nos ensaios com a presença de solução a perda de volume das trilhas foi cerca de 6 vezes superior à dos ensaios realizados a seco. Ao se introduzir uma solução no sistema, observou-se redução nos valores dos coeficientes de atrito entre $15 \%$ e $30 \%$;

Em termos de resistência ao desgaste, às juntas soldadas como metal de adição AWS ER80S-G, de maior resistência mecânica, não apresentaram diferenças significativas se comparadas àquelas soldadas com o metal de adição AWS ER70S-6. Os resultados do presente trabalho indicam que para esse aço, em termos de resistência ao desgaste, é mais vantajoso soldar com o metal de adição AWS ER70S-6, uma vez que o custo do AWS ER80S-G é mais elevado.

\section{AGRADECIMENTOS}

Os autores agradecem a empresa Arcelor Mittal S.A ${ }^{\circledR}$ pelo fornecimento do material, ao Laboratório Multiusuário de Análise de Superfícies/UFRGS, ao Laboratório de Processamento Mineral/UFRGS e à Coordenação de Pessoal de Nível Superior (CAPES).

\section{BIBLIOGRAFIA}

[1] HOLMBERG, K., KIVIKYTÖ-REPONEN, P., HÄRKISAARI, P., et al., "Global energy consumption due to friction and wear in the mining industry”, Tribology International, v. 11, p. 116-139, 2017.

[2] BUCHELY, M. F., GUTIERREZ, J. C., LEÓN, L. M., et al., "The effect of microstructure on abrasive wear of hardfacing alloys", Wear, v. 259, n. 1-6, pp. 52-61, 2005.

[3] CONORADO, J. J., CAICEDO, H. F., GÓMEZ, A. L., "The effects of welding processes on abrasive wear resistance for hardfacing deposits", Tribology International, v. 42, pp. 745-749, 2009.

[4] ESPALLARGAS, N., MISCHLER, S., "Dry wear and tribocorrosion mechanisms of pulsed plasma nitrided Ni-Cr alloy”, Wear, v. 270, pp. 464-471, 2011.

[5] SINGLA, Y. K., ARORA, N., DWIVEDI, D. K., "Dry sliding adhesive wear characteristics of Fe-based hardfacing alloys with different $\mathrm{CeO}_{2}$ additives - A statistical analysis", Tribology International, v. 105, pp. 229-240, 2017.

[6] LEITNER, M., PICHLER, P., STEINWENDER, F., GUSTER, C., "Wear and fatigue resistance of mild steel components reinforced by arc welded hard layers", Surface \& Coatings Technology, v. 330, pp. 140-148, 2017.

[7] ROSHANGHIAS, A., BARZEGARI, M., KOKABI, A. H., et al., "The effects of functionally graded material structure on wear resistance and toughness of repaired weldments", Materials \& Design, v. 32, n. 2, pp. 892-899, 2011.

[8] GARCÍA, A., VARELA, A., MONTERO, J., MIER, J. L., et al., "Tribological behaviour of an A355 steel pipe welding”, Materials Science Forum, v. 587-588, pp. 360-364, 2008.

[9] ROJACZ, H., PAHR, H., BAUMGARTNER, S., et al., "High temperature abrasion resistance of differently welded structural steels", Tribology International, v. 113, pp. 487-499, 2017. 
[10] MORCILlO, M., CHICO, B., DÍAZ, H., et al., "Atmospheric corrosion data of weathering steels. A review", Corrosion Science, v. 77, pp. 6-24, 2013.

[11] ESAB, CATÁLOGO DE CONSUMÍVEIS,

http://www.esab.com.br/br/pt/support/documentation/upload/catalogo-consumiveis-esab.pdf. Acessado em abril de 2018.

[12] ANÔNIMO (2016), ASTM G-133: Standard Test Method for Linearly Reciprocating Ball-on-Flat Sliding Wear. West Conshohocken, PA, ASTM - American Society for Testing and Materials.

[13] DAVIS, C. L., KING, J. E., "Cleavage initiation in the intercritically reheated coarse-grained heataffected zone: Part I. Fractographic evidence", Metallurgical and Materials Transactions A, v. 25, n. 3, pp. 563-573, 1994.

[14] LAMBERT-PERLADE, A., STUREL, T., GOURGUES, A. F., et al., "Mechanisms and modeling of cleavage fracture in simulated heat-affected zone microstructures of a high-strength low alloy steel", Metallurgical and Materials Transactions A. v. 35, n. 3, pp. 1039-1053, 2004.

[15] AMER, E. A., KOO, M. Y., LEE, K. H., et al., "Effect of welding heat input on microstructure and mechanical properties of simulated HAZ in Cu containing microalloyed steel", Journal of Materials Science, v. 45, n. 5, pp. 1248-1254, 2010.

[16] RAMADOSS, R., KUMAR, N., DASH, S., et al., "Wear mechanism of CrN/NbN superlattice coating sliding against various counter bodies", Int. Journal of Refractory Metals and Hard Materials, v. 41, pp.547$552,2013$.

[17] WAINER, E., BRANDI, S. D., MELLO, F. D. H. Soldagem: processos e metalurgia, São Paulo, Edgard Blucher LTDA, 2004

[18] LANCASTER, J. F., Metallurgy of welding, 6ed, Wood head Publishing, 1999.

[19] CHO, C., LEE, Y., "Effects of oxide layer on the friction characteristics between TiN coated ball and steel disk in dry sliding", Wear, v. 254, n. 3-4, pp. 383-390, 2003.

[20] SHARMA, S., SANGAL, S., MONDAL, K., "Influence of subsurface structure on the linear reciprocating sliding wear behavior of steels with different microstructures", Metallurgical and Materials Transactions A, v. 45, n. 13, pp. 6088-6102, 2014.

[21] BAKSHI, S., SHIPWAY, P., BHADESHIA, H. K. D. H., "Three-body abrasive wear of fine pearlite, nanostructured bainite and martensite", Wear, v. 308, n. 1-2, pp. 46-53, 2013.

[22] BABU, S. S., "The mechanism of acicular ferrite in weld deposits", Current Opinion in Solid State and Materials Science, v. 8, n. 2-3, pp. 267-278, 2004.

[23] XU, X., XU, W., EDERVEEN, F. H., et al., "Design of low hardness abrasion resistant steels", Wear, v. 301, n. 1-2, pp. 89-93, 2013.

[24] JHA, A. K., PRASAD, B. K., MODI, O. P., et al., "Correlating microstructural features and mechanical properties with abrasion resistance of a high strength low alloy steel", Wear, v. 254, pp.120-128, 2003.

[25] FINDIK, F., "Latest progress on tribological properties of industrial materials", Materials and Design, v. 57, p. 218-244, 2014.

[26] MOERLOOZE, K., AL-BENDER, F., "On the relationship between normal load and friction force in pre-sliding frictional contacts. Part 2: Experimental investigation”, Wear, v. 269, pp. 183-189, 2010.

[27] VIÁFARA, C. C., SINATORA, A., "Unlubricated sliding friction and wear of steels: An evaluation of the mechanism responsible for the T1 wear regime transition”, Wear, v. 271, pp. 1689-1700, 2011.

\section{ORCID}

Daniela Fátima Giarollo

Cíntia Cristiane Petry Mazzaferro

José Antônio Esmerio Mazzaferro https://orcid.org/0000-0003-1292-3171

https://orcid.org/0000-0002-8957-6051

https://orcid.org/0000-0002-8042-5695 